\title{
Effects of late defoliations on chemical and sensory characteristics of cv. Uva Longanesi wines
}

\author{
P. Tessarin ${ }^{1}$, A. C. Boliani' ${ }^{2}$, R. V. Botelho ${ }^{3}$, C. Rusin ${ }^{1}$, A. Versari ${ }^{4}$, G. P. Parpinello ${ }^{4}$ and
} A. D. Rombolà ${ }^{1 *}$

${ }^{1}$ Department of Agricultural Sciences, University of Bologna, 40127, Bologna (BO), Italy. *Corresponding author:adamo.rombola@unibo.it.

${ }^{2}$ Department of Phytotecnic, Food Sciences and Socio-Economy, Faculty of Agricultural Engineering, State University Paulista, CEP: 15385-000, Ilha Solteira, São Paulo, Brasil.

${ }^{3}$ Department of Agronomy, State University of Mid-Western, Campus Cedeteg, CEP 85040-080 Guarapuava, Paraná, Brasil.

${ }^{4}$ Department of Agricultural and Food Sciences, University of Bologna, 47521, Cesena (FC), Italy.

\begin{abstract}
In this study we investigated the effects of late leaf removal on the berry and wine composition and on wine sensory characteristics of Uva Longanesi, a late maturing red Italian grape variety, which wines are characterized by high levels of alcohol and excessive astringency, the latter apparently intensified by late defoliation practices. During 2008 season, spur-pruned trained vines were submitted to manual defoliation (4 basal leaves) at the onset (DEF I, 210 DOY) or at the end (DEF II, 231 DOY) of veraison and compared with non-defoliated plants (CON). On every DEF II vine, since defoliation until harvest, a cluster was shaded (DEF II + shading). A decrease of the berry soluble solids and skin anthocyanins was found in DEF I vines. Defoliation modified composition and sensory characteristics of wine with DEF II having higher alcohol strength and astringency compared to DEF I, whereas CON wines displayed intermediate values. The practice and timing of partial late defoliation greatly affected the chemical and sensory attributes of wine.
\end{abstract}

Keywords: Vitis vinifera, grapevine, leaf removal, polyphenols, sensory analysis 


\section{Introduction}

Uva Longanesi is an autochthonous grape variety mainly cultivated in North Italy, in a plain and nearby foothill areas of EmiliaRomagna region (Ravenna, Italy), currently covering around 500 hectares. Due to its oenological qualities and cultural value for local viticulture, this cultivar has been included in the National Register of Vine Varieties (Marangoni et al. 2000). However, the limited number of scientific researches on cv. Uva Longanesi was mainly focused on historical and ampelographic aspects, marketing strategies and wine chemical composition (Marangoni et al. 2000, Sartini et al. 2000, Kelm et al. 2012). For this reason growers have been often facing agronomical and quality related problems such as susceptibility to pathogens, high astringency of grapes with little availability of adequate technical and scientific support to manage these issues. Moreover, wines obtained from this variety are characterized by a strong, often undesired, astringency; however, the high levels of total phenols, including anthocyanins, make Uva Longanesi wines suitable for aging in wooden barrels (Fontana 2000). Astringency, the drying and puckering sensations in the mouth (ASTM 1989) elicited by the binding of phenolic compounds (e.g. tannins) to salivary proteins, represents one of the most important sensory attributes of red wines. However, to a great extent, this characteristic is not well accepted by consumers and tasters. For this reason, winemaking practices must avoid excessive extraction of astringent compounds (i.e. by selection of grapes with appropriate phenolic maturity, reduced seed breakage during crushing, short macerations without seeds).
Canopy management is considered to have a crucial effect on flavonoids accumulation and beside of winemaking practices devoted to color improvement and astringency reduction. An effective approach could be undertaken through the adoption of field practices which control vegetative growth of vines (shoot, tip and leaf removal) that might influence the accumulations of flavonoids in the berry through both direct (i.e. changes of source-sink relationship) and indirect (i.e. modified microenvironment) effects. Defoliation is a widespread, mechanizable canopy management practice that can be carried out between pre-bloom and fruit set at veraison or in post-veraison. The effects on quality parameters seem to be related to the timing of selective defoliation (Bledsoe et al. 1998, Intrieri et al. 2008, Poni et al. 2009, Palliotti et al. 2013, Pastore et al. 2013, Poni et al. 2013); which influences the source-sink balance, and to the modified microclimate around the clusters. In particular, the effect of early (pre-bloom-fruit set) defoliation on grape quality parameters (Poni et al. 2006, Guidoni et al. 2008, Diago et al. 2010) and vineyard efficiency in terms of gas exchange, source-to-sink balance and reserve storage responses (Palliotti et al. 2011) have been reported.

Late defoliation (performed at the onset of veraison or later) is a frequently adopted practice for Uva Longanesi variety, consisting in removing 4-6 basal leaves of the shoot to allow air circulation, light radiation and pesticides penetration at the level of the cluster. The result is the establishment of a microclimate contrasting the development of fungal diseases 
(e.g. Botrytis), thus allowing healthy bunches to be maintained on the vine up to the beginning of autumn, characterized by frequent rains and high air humidity, when they are traditionally harvested. In cv. Sangiovese, the removal of the bunch zone leaves, at veraison (8 Brix), had a strong impact on berry temperature exposure but a limited effect on the source sink-balance (Pastore et al. 2013), that might be due to the lower photosynthetic activity of basal compared to the intermediate and apical leaves (Poni et al. 1994, Kriedemann et al. 1970). The time after veraison at which this practice is performed could influence substantially the grape physiology, since basal leaves lose their photosynthetic activity gradually during ripening. Leaf removal at veraison (5 Brix), performed on cv. Cabernet Sauvignon plants, had a diminishing effect on gene expression of the sugar transporter HT1, detected one week later; however, the treatment did not modify the soluble solids concentration, measured at harvest (Matus et al. 2009). On $\mathrm{cv}$. Sangiovese potted vines, the removal of leaves inserted above the bunch zone in postveraison (12 Brix), was more effective than defoliation imposed at berry growth lag-phase, in temporarily decreasing berry soluble solids concentration compared to the control (Poni et al. 2013). In addition, mechanical defoliation applied in post-véraison (16-17 Brix), by removing at least $30-35 \%$ of vine leaf area apical to the bunch zone, determined the achievement of an effective delay in cv. Sangiovese berries soluble solids accumulation (Palliotti et al. 2013).

In different species, including blueberry (Vaccinium corymbosum) and murtilla (Ugni molinae), fruit polyphenol concentration may be influenced by several factors (e.g. variety, maturity stage, environment, growing season, meteorological conditions, soil type, light, etc.), which could also affect both fruit antioxidant content and activity (Ribera et al. 2010; Alfaro et al. 2013).

In particular, the composition of the grape berry can be influenced by both direct (e.g. intensity and quality of light) and indirect (temperature-mediated) effects of sunlight exposure (Bergqvist et al. 2011). For this reason, allowing the clusters to be completely exposed to the sun might lead, in warm climates, to compromised fruit composition because of excessive temperature, with a consequent sharp drop in titratable acidity (Bergqvist et al. 2011) and hinder color formation (Kliewer et al. 1977, Haselgrove et al. 2000, Bergqvist et al. 2011). On the other hand, canopy shading has been shown to have significant effect on flavonoids accumulation; in particular, the shading of clusters may hinder anthocyanins accumulation (Morrison and Noble 1990, Dokoozlian and Kliewer 1996, Chorti et al. 2010, Bergqvist et al. 2011), as heavily shading conditions can be a limiting factor especially in the early stages of maturation (Haselgrove et al. 2000, Li et al. 2013). The effects of light on fruit composition are closely dependent to berry temperature elevation as a consequence of increased sunlight exposure, because high berry temperature can inhibit color development (Bergqvist et al. 2001, Mori et al. 2004, Yamane et al. 2006, Tarara et al. 2008). Moreover, the influence of temperature can vary greatly depending on the stage of berry development (Yamane et al. 2006).

A technological equilibrium between sugar and phenolic content at harvest is difficult to 
achieve and this is particularly true in variety such as Uva Longanesi, characterized by high astringency. For these reasons, there is a need of new viticultural practices finalized to the production of wine at lower alcohol content without affecting the overall wine quality.

The research was aimed to assess in cv. Uva Longanesi the effects of late defoliations, implemented at the beginning or the end of veraison, on berry total soluble solids, qualitative and quantitative berry anthocyanin profile (the latter not being determined before in this cultivar) and chemical and sensory properties of wines.

\section{Materials and methods}

\subsection{Plant material and field measurements}

The experiment was performed in 2008, in a mature non-irrigated vineyard (planted in 2000) of cv. Uva Longanesi, Vitis vinifera L., grafted onto SO4, trained to high spur pruned cordon (VSP), located in the Po Valley area $\left(44^{\circ} .41 \mathrm{~N}\right.$, $11^{\circ} .98^{\prime} \mathrm{E}$, Bagnacavallo, Ravenna, Italy), with east-west oriented rows. Vines were spaced 3.3 x $1.7 \mathrm{~m}$ (1783 plants/ha). The soil presented silty clay loam texture, sub-alkaline $\mathrm{pH}$ (8.02), high total carbonate concentration (19\%) active lime level $(13 \%)$ and percentage of organic matter (3.4\%). The natural vegetation, mainly grasses, was maintained in the alleys and controlled by periodical cuttings, whereas glyphosate was applied along the row, once in spring.

Since budburst to the beginning of veraison, the average air temperature increased from 10 to $15^{\circ} \mathrm{C}$, whereas total rainfall was about $200 \mathrm{~mm}$ (www.arpa.emr.it). The average air temperature value, recorded at the time of DEF I imposition (July 28, beginning of veraison), was $25^{\circ} \mathrm{C}$, the minimum $15^{\circ} \mathrm{C}$ and the maximum $35{ }^{\circ} \mathrm{C}$. In the following 3 weeks, maximum temperature exceeded $35{ }^{\circ} \mathrm{C}$, also at DEF II treatment imposition (August 18, 21 DAV). At the beginning of September, the average temperatures were in a range between $20-25^{\circ}$ $\mathrm{C}$, decreasing below $15^{\circ} \mathrm{C}$, close to the harvest (www.arpa.emr.it). Rainfall recorded from veraison to harvest was about $60 \mathrm{~mm}$ (www. arpa.emr.it)

Bud and bunch number was adjusted by winter pruning and cluster thinning to a number of 21 bunches per vine. The experiment was performed on plants selected according to correct vine balance (crop load vs. leaf area ratio), evaluated through visual inspection and capable of ensuring a proper grape ripening according to the local experience (vines with around one square meter of leaf area per expected kilogram of grapes). Shoot growth terminated 1 week before veraison. Three treatments with 5 replicates, of two plants each, were imposed in a completely randomized design on vines located in the same row: CON (control); DEF I (leaf removal at the beginning of veraison, (10 Brix), July 28 (DAV0); DEF II (leaf removal at the end of veraison, 17 Brix, August 18, DAV 21). An additional treatment, $\mathrm{DEF}+\mathrm{SH}$ (leaf removal at the end of veraison, (DAV 21) + shading, was included by inserting, since leaf removal until harvest, on every DEF II vine, one cluster into a tetrapak box, provided with lateral openings able to reduce the solar radiation of $95 \%$ (confirmed by measurements performed by a Skye Display Meter, Skye Instruments Ltd, UK).

In vines subjected to defoliation, four basal leaves per shoot, corresponding to $0.07 \mathrm{~m}^{2}(12 \%$ of the total shoot area, $0.58 \mathrm{~m}^{2}$ ) were removed. 
Laterals were maintained in all treatments. At the time of treatments imposition, plants presented 14 shoots and an average leaf area of $8.1 \mathrm{~m}^{2}$. At the end of veraison, 7 shoots per treatment were sampled to assess leaf surface removed through defoliation. Total leaf surface on the main shoots and shoot laterals was determined with a $\mathrm{Li}$ 3000A leaf area meter (Li-Cor, Biosciences, Lincoln, Nebraska, USA). Defoliation was not followed by leaf regrowth.

Measurements performed during the course of the experiment made it possible to verify that the difference of temperature between shaded clusters (DEF II $+\mathrm{SH}$ ) and bunches of defoliated plants (portion of cluster exposed to light) (DEF II) remained around $\pm 2{ }^{\circ} \mathrm{C}$.

Leaves and clusters temperature was detected every week starting at the end of veraison until harvest, at 9 am and $3 \mathrm{pm}$, through infrared thermometer Raytek Raynger ${ }^{\mathrm{TM}}$ ST. Since the rows were oriented East-West, in the morning data were collected on the North-facing vegetative wall, while in the afternoon the South-facing one was monitored.

\subsection{Analysis of berries}

The following parameters were analysed: berry weight; expressed as $\mathrm{g}$ per berry (technical balance Gibertini Elettronica S.r.l., Milan, Italy); total soluble solids (TSS; Brix; Electronic Refractometer Maselli Misure S.P.A., Parma, Italy), titratable acidity (TA; expressed as $\mathrm{g} / \mathrm{L}$ of tartaric acid) and $\mathrm{pH}$ (Crison Compact Titrator, Crison Instrument SA, Barcelona, Spain) were periodically determined by collecting 50 berries per replicate since veraison until harvest. At harvest, productive parameters: number of clusters per plant, productivity per vine $(\mathrm{kg})$ and bunch weight (g) (Wunder Digital Dynamometer, Wunder SA-Bi S.r.1, Milan, Italy, were determined. Plants subjected to the different treatments were harvested in the same day, on October 9, DAV 73.

At harvest, additional samples (25 berries) were collected for anthocyanins qualitative and quantitative profile. Grape extract was obtained from each sample (Mattivi et al. 2006) and analyzed by an HPLC, equipped with a UV detector and reversed phase column (LiChrospherRP-18 250×4 mm $5 \mu \mathrm{m}$ column). The solvents were (A) aqueous $10 \%$ formic acid, and (B) acetonitrile. The flow rate was $1.1 \mathrm{~mL} /$ $\mathrm{min}$ in a gradient method of initial isocratic flow of $96 \%$ A for $8 \mathrm{~min}, 85 \%$ A for $15 \mathrm{~min}$, from $85 \%$ to $70 \%$ A for $20 \mathrm{~min}$, isocratic $96 \%$ A for $2 \mathrm{~min}$. Injection volumes were $150 \mu \mathrm{L}$, and the detection wavelength was $520 \mathrm{~nm}$ (Mattivi et al. 2006). All individual anthocyanins were quantified $(\mathrm{mg} / \mathrm{L})$ by means of a calibration curve obtained with malvidin-3-glucoside. The HPLC analysis of cv. Uva Longanesi provided a qualitative profile including 15 anthocyanins: the monoglucosides of delphinidin (Df-3-glc), cyanidin (Cn-3-glc), petunidin (Pt-3-glc), peonidin (Pn-3-glc), and malvidin (Mv-3-glc), their acetylated derivatives (Df-3-acetylglc, Cn-3-acetylglc, Pt-3-acetylglc, Pn-3-acetylglc and Mv-3-acetylglc) and their p-coumarylated derivatives (Df-3-cumaroylglc, Cn-3-cumaroylglc, Pt-3-cumaroylglc, Pn-3cumaroylglc, Mv-3-cumaroylglc).

\subsection{Grape and Winemaking protocol}

For winemaking purposes, samples of cv. Uva Longanesi were harvested at the technological stage of ripening at the beginning of October 2008. Four small volume $(5 \mathrm{~kg}$ of grapes 
harvested from 2 plants) vinifications (Sampaio et al. 2007) were performed for each thesis CON, DEF I and DEF II. Briefly, grapes where manually destemmed and crushed into a 5 liters glass tank while supplying carbonic snow to avoid oxidation. Before any addition, sampling from each tank was performed to the evaluation of basic chemical parameters of must: yeast available nitrogenous compounds (YANC, $\mathrm{mg} / \mathrm{L}$ ), sugar (Brix) $\mathrm{pH}$, total acidity (TA, $\mathrm{g} / \mathrm{L})$. Afterwards, must was added with sodium metabisulfite $(20 \mathrm{~g} / \mathrm{hL})$, di-ammonium phosphate (up to $200 \mathrm{mg} / \mathrm{L}$ ) and selected yeast $(20 \mathrm{~g} /$ hL; F15 Laffort, Bordeaux, France). Contact between marc and must was improved by means of trellises (racks). Tanks were provided with valves for venting of $\mathrm{CO}_{2}$, temperature sensor and protected from the light with aluminum foil. Temperature was set up at $20^{\circ} \mathrm{C}$ and the fermentation pattern was monitored through weight reduction. Temperature and weight were recorded every 48 hours. At the end of fermentation (reducing sugars below $3 \mathrm{~g} / \mathrm{L}$ ), both free run wine and wine extracted from marc with a laboratory piston press ( 2 bar) were collected and pooled. Then wines were added with $\mathrm{SO}_{2}$ (up to $100 \mathrm{mg} / \mathrm{L}$ as a total $\mathrm{SO}_{2}$ ), bentonite (8 $\mathrm{mg} / \mathrm{L})$ and after clarification were bottled and kept at $4{ }^{\circ} \mathrm{C}$ until chemical and sensory analyses.

\subsection{Wine analyses}

Wines ( 3 treatments $\times 4$ replicates $=12$ samples $)$ were analyzed for alcohol strength (AS, \%), dry matter (DM, g/L), pH, total acidity (TA, g/L), volatile acidity (VA, g/L), reducing sugars $(\mathrm{RS}$, $\mathrm{g} / \mathrm{L})$, optical density (AU) at 420, 520 and 620 $\mathrm{nm}$, total color intensity $(\mathrm{CI}, \mathrm{AU})$ and tonality
(CH, AU), European Official Methods. Total and free sulfure dioxide $(\mathrm{mg} / \mathrm{L}$, Ripper and Schmitt 1896), anthocyanins (mg/L, Arfelli et al. 1992) and phenolics (mg/L, Castellari et al. 2002) were also determined. The gelatin index (GI, Glories 1978) was evaluated in duplicate for each treatments.

\subsection{Sensory evaluation}

Paired comparison tests were performed to determine differences in terms of astringency among the three wines obtained with different canopy management (Lowless and Heymann 1998) Thirty-four assessors (19 females and 15 males aged between 21 and 64) recruited among employers and students of the Campus of Food Science (Cesena, Italy) participated in the evaluation session. Two wines belonging to each thesis were object of study. The two tasting sessions took place in different days. For each comparisons (CON vs. DEF I; CON vs DEF II, DEF I vs DEF II) assessors were presented with two transparent glasses (ISO 3591,1977 ) containing $30 \mathrm{ml}$ of wine and asked to taste wines from left to right and identify the sample characterized by highest astringency. Samples were coded with a three-digit numbers and distributed according to a completely randomized order.

\subsection{Statistics}

Comparison of means and analysis of variance between treatments were done by using SAS 6.04 software (SAS INSTITUTE, CARY, NC, USA). Means were compared by the StudentNewman-Keuls test $(P \leq 0.05)$. 
Bunch weight and tri-hydroxylated to dihydroxylated ratio were subjected to Kruskall Wallis non-parametric test and means compared by Dunn's multiple comparison test using Prism ${ }^{\circledR} 5$ (GraphPad Software, Inc.).

Differences in chemical composition of wines were analyzed by means of one-way ANOVA with Fisher's LSD post-hoc test with statistical significance at $p<0.05$ using XLSTAT 2010.3 version (Addinsoft, Anglesey, UK). For sensory analysis, results were evaluated using binomial distribution table for one-tailed test (Lowless and Heymann. 1998).

\section{Results}

\subsection{Bunch weight and plant productivity}

Defoliation did not affect bunch weight (CON: 361 g; DEF I: 395 g; DEF II: 347 g) and productivity per plant (CON: $7.6 \mathrm{~kg}$; DEF I: 8.1 $\mathrm{kg}$; DEF II: $7.7 \mathrm{~kg}$ ). Leaf area to yield ratio in control vines $\left(1.02 \mathrm{~m}^{2}\right)$ was significantly higher than in DEF I $\left(0.82 \mathrm{~m}^{2}\right)$ and DEF II $\left(0.82 \mathrm{~m}^{2}\right)$ plants.

\subsection{Temperature of CON and DEFs grapes}

Since the end of veraison to harvest, morning temperatures of exposed bunches were higher in defoliated vines (Table 1). Similar results were observed by afternoon measurements, with the only exception of harvest time (283 DOY; Table 2). Treatment did not modify the morning temperature of the shaded portion of the cluster, while in the afternoon, DEF II plants, presented slight, but significant increases in the temperature compared to control vines (data not shown).
3.3. Berry composition: average weight, total soluble solids, total acidity, $\mathrm{pH}$ of CON and DEFs grapes

Leaf removal at the onset of veraison (DEF I) resulted in a decrease of the berry total soluble solids (TSS) concentration, recorded from the end of veraison until harvest (with the exception of data collected on September 17, DAV 51) (Table 3). Defoliation performed at the end of veraison (DEF II) presented intermediate values between DEF I and control, without showing significant differences with these treatments (Table 3). Clusters-shading (DEF II + SH), induced the lowest TSS concentration in the berries (Table 3). Defoliation did not modify berry weight (CON: $1.9 \mathrm{~g}$; DEF I: $1.9 \mathrm{~g}$ and DEF II: $1.7 \mathrm{~g}$ ), titratable acidity (CON: $7.49 \mathrm{~g} / \mathrm{L}$; DEF I: $7.71 \mathrm{~g} / \mathrm{L}$; DEF II: $7.50 \mathrm{~g} / \mathrm{L}$ ) and $\mathrm{pH}$ of the juice (CON: 3.46; DEF I: 3.39; DEF II: 3.41) at harvest, furthermore these parameters presented similar values during ripening (data not shown).

\subsection{Berry composition: anthocyanins of CON and DEFs grapes}

Fifteen individual anthocyanins were identified in the Uva Longanesi berry skins: glucosides of delphinidin, cyanidin, petunidin, peonidin and malvidin (Table 4), and their acylated (acetic or cumaric acids) forms. Not acylated monoglucoside anthocyanins predominate over acetylglucosidated and p-coumarilglucosidated forms; Malvidin-3-acetylglucosyde was the major acylated anthocyanin; traces of $\mathrm{Cn}$ acetylglc, Df-cumaroylglc and Cn-cumaroylglc were found in some samples, regardless of treatments (data not shown). Tri-hydroxylated and di-hydroxylates forms represented $94.5 \%$ and $5.5 \%$ of the total not acylated anthocyanins 
(Table 4). With regard to the not acylated component, treatment DEF I showed a significant decrease in the concentration of Mv-3-glc and Pn-3-glc (Table 4). Moreover, similarly to DEF I treatment, DEF II and DEFII + SH showed lower values of Mv-3-glc and Pn-3-glc, respectively, when compared to CON.

Only defoliation performed at the beginning of veraison determined a significant decrease of both $3^{\prime} 4^{\prime}-\mathrm{OH}$ and $3^{\prime} 4^{\prime} 5^{\prime}-\mathrm{OH}$ anthocyanins concentrations compared to the control, whereas the concentration of these compounds were similar when comparing DEF I and DEF II treatments.

\subsection{Chemical composition of $\mathrm{CON}$ and DEFs musts and wines}

Leaf removal carried out at the beginning of veraison (DEF I) as well as DEF II + SH treatment resulted in a decrease in must TSS concentration at harvest whereas DEF II treatment did not show statistically significant differences compared to CON (Table 3). No significant differences in relation to $\mathrm{pH}$ and titratable acidity of musts at harvest were detected. Yeast available nitrogenous compounds (YANC) presented significantly lower values in vines undergone to leaf removal (DEF I: $87.1 \mathrm{mg} / \mathrm{L}$; DEF II 68.6 $\mathrm{mg} / \mathrm{L})$ respect to the control $(124.9 \mathrm{mg} / \mathrm{L})$. The temperature during alcoholic fermentation (AF) ranged between 22.5 and $19.1^{\circ} \mathrm{C}$. The AF was considered completed in 25 days whit tanks achieving in the last 4 days a constant weight. Canopy management did not have significant effect on wine yield (average data for $\mathrm{CON}$ : 59.5\%; DEF I: 58.8\%; DEF II 59.1\%). The wines were sampled and analyzed for the main chemical and color related parameters: $\mathrm{pH}$, total acidity (TA), volatile acidity (VA), alcohol strength (AS), total dry matter (DM), reducing sugars (RS), color intensity $(\mathrm{CI})$, color hue $(\mathrm{CH})$, total sulfur dioxide content $\left(\mathrm{SO}_{2}\right)$. Average value from four winemaking replicates of each thesis (CON, DEF I e DEF II) are reported in Table 5.

\subsection{Analysis of anthocyanins and simple} phenolic compounds in CON and DEFs wines

The analysis of phenolic compounds revealed a qualitative profile comparable to those usually obtained in other Uva Longanesi wines (Sartini et al, 2000). Average data (mean of analyses carried out in four vinifications) are summarized in Table 6. If compared to data already available in literature all wines were characterized by a high content in all analyzed phenols. The HPLC analysis of anthocyanins did not highlight significant differences in terms of Malvidin3-glucoside, which was the most important anthocyanin in all wines (ranging between 186 and $240 \mathrm{mg} / \mathrm{L}$ ) as well as in Delphinidin-3glucoside, Peonidin-3-glucoside and Cianidin3-glucoside. No significant differences emerged among anthocyanidins-3-acetylglucoside, with Malvidin-3-acetylglucosideachieving thehighest concentration (CON: 66.02; DEF I: 52.16; DEF II: $54.41 \mathrm{mg} / \mathrm{L}$ ). Among the anthocyanidins-3coumaroylglucoside the Peonidin+Malvidin was the major compounds with significantly higher concentration in CON (22.76 vs 15.10 and $15.93 \mathrm{mg} / \mathrm{L})$. Other differences were found for Petunidin3-coumaroylglucoside (CON: 4.15; DEF I:3.40; DEF II: $3.27 \mathrm{mg} / \mathrm{L}$ ) whereas the others compounds were comparable. The analysis of phenolics brought out the high content of monomeric compounds such as phenolic and cinnamic acids (gallic, coutaric 
and caftaric) as well as flavonols $((+)$ catechin $(-)$-epicatechin). In particular, gallic, coutaric and caftaric acids decreased significantly in DEF I wines in comparison with CON wines but were not different from DEF II wines. As regards flavanols, that are compounds that contribute to the astringency and bitterness of the wine, late defoliation (DEF II) determined a reduction in (-) epicatechin in comparison to $\mathrm{CON}$ and DEF I with value of $78.28,90.23$ and $81.16 \mathrm{mg} / \mathrm{L}$, respectively. Conversely, in flavonols, rutin was increased by defoliation at the beginning of veraison ( 7.50 vs 5.83 and $5.36 \mathrm{mg} / \mathrm{L}$ ) whereas this management induced an opposite effect in myricetin concentration. At last, defoliation was responsible of reduction of trans-resveratrol concentration (CON: 2.15; DEF I: 1.40; DEF II: $1.55 \mathrm{mg} / \mathrm{L})$.

In order to get more insights about possible effect of defoliation on astringency the gelatin index (GI) of wines was evaluated. This assay is considered to be helpful in determining the ability of tannins to react with proteins, and, as a consequence, to measure astringency. The obtained results (Table 5) indicate that defoliation can reduce the GI when performed at the beginning of veraison (32.52), unlike of leaf removal at the end of veraison (34.92).

Table 1. Effect of treatments on the temperature of the cluster portion exposed to light, measured at 9 am (Ravenna, Italy, 2008) (mean value and standard deviation).

\begin{tabular}{lcccccc}
\cline { 2 - 6 } Treatment & \multicolumn{7}{c}{ Date } \\
\cline { 2 - 7 } & Aug-19 & Aug-27 & Sep-02 & Sep-09 & Sep-17 & Oct-09 \\
\hline CON & $27.38 \pm 3.09 \mathrm{c}$ & $26.30 \pm 3.06 \mathrm{~b}$ & $25.69 \pm 1.90 \mathrm{~b}$ & $28.16 \pm 2.21 \mathrm{~b}$ & $21.78 \pm 1.61 \mathrm{~b}$ & $15.77 \pm 1.40 \mathrm{~b}$ \\
DEF I & $34.17 \pm 3.30 \mathrm{~b}$ & $32.73 \pm 2.20 \mathrm{a}$ & $28.63 \pm 2.61 \mathrm{a}$ & $34.79 \pm 3.74 \mathrm{a}$ & $23.78 \pm 1.76 \mathrm{a}$ & $22.90 \pm 1.12 \mathrm{a}$ \\
DEF II & $37.42 \pm 2.70 \mathrm{a}$ & $31.85 \pm 2.85 \mathrm{a}$ & $29.59 \pm 2.42 \mathrm{a}$ & $32.50 \pm 4.95 \mathrm{a}$ & $23.81 \pm 1.18 \mathrm{a}$ & $23.07 \pm 0.88 \mathrm{a}$ \\
Significance & $* * *$ & $* * *$ & $* * *$ & $* * *$ & $* *$ & $* * *$ \\
\hline
\end{tabular}

Legend: CON: Control, no defoliation; DEF I: leaves removal at the beginning of veraison; DEF II: leaves removal at the end of veraison. **;**; represent significant differences between treatments at $P<0.01$ and $P=0.001$, respectively. Means followed by the same letter in each column were not significantly different according to the SNK test $(P \leq 0.05)$.

Table 2. Effect of treatments on the temperature of the cluster portion exposed to light, measured at 3 pm (Ravenna, Italy, 2008) (mean value and standard deviation).

\begin{tabular}{lcccccc}
\cline { 2 - 6 } Treatment & \multicolumn{7}{c}{ Date } \\
\cline { 2 - 7 } & Aug-19 & Aug-27 & Sep-02 & Sep-09 & Sep-17 & Oct-09 \\
\hline CON & $31.04 \pm 2.11 \mathrm{c}$ & $29.61 \pm 1.40 \mathrm{~b}$ & $30.72 \pm 1.21 \mathrm{c}$ & $31.16 \pm 1.73 \mathrm{~b}$ & $24.17 \pm 1.59 \mathrm{c}$ & $20.86 \pm 0.57$ \\
DEF I & $34.25 \pm 3.33 \mathrm{~b}$ & $32.73 \pm 3.10 \mathrm{a}$ & $34.93 \pm 3.23 \mathrm{~b}$ & $37.73 \pm 3.90 \mathrm{a}$ & $27.55 \pm 3.74 \mathrm{~b}$ & $21.08 \pm 1.15$ \\
DEF II & $38.10 \pm 1.20 \mathrm{a}$ & $34.17 \pm 4.22 \mathrm{a}$ & $37.86 \pm 2.57 \mathrm{a}$ & $38.69 \pm 2.81 \mathrm{a}$ & $30.73 \pm 2.44 \mathrm{a}$ & $21.26 \pm 0.78$ \\
Significance & $* * *$ & $* *$ & $* * *$ & *** & *** & n.s. \\
\hline
\end{tabular}

Legend: CON: Control, no defoliation; DEF I: leaves removal at the beginning of veraison; DEF II: leaves removal at the end of veraison; n.s., not significant; **, ***; represent significant differences between treatments at $P<0.01$ and $P=0.001$, respectively. Means followed by the same letter in each column were not significantly different according to the SNK test $(P \leq 0.05)$. 
Table 3. Effect of treatments on berry total soluble solids, TSS (Brix) (mean value and standard deviation).

\begin{tabular}{|c|c|c|c|c|c|c|c|}
\hline Treatment & Aug-18 & Aug-26 & Sep-01 & Sep-09 & Sep-17 & Sep-29 & Oct-09 \\
\hline $\mathrm{CON}$ & $17.42 \pm 0.89 \mathrm{a}$ & $19.66 \pm 0.67 \mathrm{a}$ & $21.20 \pm 0.65 \mathrm{a}$ & $23.22 \pm 0.18 \mathrm{a}$ & $23.73 \pm 0.70$ & $25.20 \pm 0.49 \mathrm{a}$ & $26.28 \pm 0.11 \mathrm{a}$ \\
\hline DEF I & $15.06 \pm 0.95 \mathrm{~b}$ & $17.77 \pm 0.83 \mathrm{~b}$ & $19.83 \pm 0.94 \mathrm{~b}$ & $21.69 \pm 0.31 \mathrm{~b}$ & $22.63 \pm 1.00$ & $23.58 \pm 0.65 \mathrm{~b}$ & $24.84 \pm 0.48 \mathrm{~b}$ \\
\hline DEF II & $16.56 \pm 0.76 \mathrm{a}$ & $18.80 \pm 0.84 \mathrm{ab}$ & $20.32 \pm 0.69 \mathrm{ab}$ & $22.60 \pm 0.74 \mathrm{a}$ & $23.42 \pm 0.83$ & $24.45 \pm 0.77 \mathrm{ab}$ & $25.60 \pm 0.32 \mathrm{ab}$ \\
\hline DEF II+ SH & - & - & - & - & - & - & $23.96 \pm 2.03 \mathrm{c}$ \\
\hline Significance & $*$ & * & $*$ & $* *$ & n.s. & $*$ & $* * *$ \\
\hline
\end{tabular}

Legend: CON: Control, no defoliation; DEF I: leaves removal at the beginning of veraison; DEF II: leaves removal at the end of veraison; DEF II + SH: leaves removal at the end of veraison + shading; n.s., not significant; , **;***; represent significant differences between treatments at $P<0.05, P<0.01$ and $\mathrm{P}=0.001$, respectively. Means followed by the same letter in each column were not significantly different according to the SNK test $(P \leq 0.05)$.

Table 4. Effect of treatments on berry glycosilated anthocyanins: Peonidin-3-glucosyde, Malvidin3-glucosyde, Petunidin-3-glucosyde, Delfinidin-3-glucosyde, Cyanidin-3-glucosyde di-substituted $\left(3^{\prime} 4^{\prime}-\mathrm{OH}\right)$, tri-substituted $\left(3^{\prime} 4^{\prime} 5^{\prime}-\mathrm{OH}\right)$ and total glycosilated anthocyanins concentrations (expressed in $\mathrm{mg} \mathrm{g}$ of berry skin) at harvest (mean value and standard deviation).

\begin{tabular}{lcccccccc} 
Treatment & Pn-3-glc & Mv-3-glc & Pt-3-glc & Df-3-glc & Cn-3-glc & $\mathbf{3}^{\prime} \mathbf{4}^{\prime}$-OH & $\mathbf{3}^{\prime} \mathbf{4}^{\prime} \mathbf{5}^{\prime}$-OH & Total-glc \\
\hline CON & $0.18 \pm 0.02 \mathrm{a}$ & $2.90 \pm 0.38 \mathrm{a}$ & $0.58 \pm 0.06$ & $0.55 \pm 0.06$ & $0.06 \pm 0.01$ & $0.25 \pm 0.03 \mathrm{a}$ & $4.02 \pm 0.50 \mathrm{a}$ & $4.27 \pm 0.50 \mathrm{a}$ \\
DEF I & $0.12 \pm 0.01 \mathrm{~b}$ & $2.18 \pm 0.23 \mathrm{~b}$ & $0.49 \pm 0.03$ & $0.50 \pm 0.05$ & $0.05 \pm 0.01$ & $0.17 \pm 0.02 \mathrm{~b}$ & $3.17 \pm 0.24 \mathrm{~b}$ & $3.34 \pm 0.25 \mathrm{~b}$ \\
DEF II & $0.15 \pm 0.02 \mathrm{ab}$ & $2.33 \pm 0.17 \mathrm{~b}$ & $0.54 \pm 0.07$ & $0.53 \pm 0.11$ & $0.07 \pm 0.01$ & $0.22 \pm 0.04 \mathrm{ab}$ & $3.40 \pm 0.30 \mathrm{ab}$ & $3.61 \pm 0.34 \mathrm{ab}$ \\
DEF II + SH & $0.13 \pm 0.02 \mathrm{~b}$ & $2.46 \pm 0.46 \mathrm{ab}$ & $0.51 \pm 0.09$ & $0.49 \pm 0.09$ & $0.05 \pm 0.01$ & $0.18 \pm 0.03 \mathrm{ab}$ & $3.46 \pm 0.62 \mathrm{ab}$ & $3.65 \pm 0.66 \mathrm{ab}$ \\
Significance & $*$ & $*$ & $n . s$. & $n . s$. & $n . s$. & $*$ & $*$ & $*$ \\
\hline
\end{tabular}

Legend: CON: Control, no defoliation; DEF I: leaves removal at the beginning of veraison; DEF II: leaves removal at the end of veraison; DEF II + SH: leaves removal at the end of veraison + shading; Df: Delphinidin; Cn: Cyanidin; Pt: Petunidin; Pn: Peonidin; Mv: Malvidin; glc: glucoside; n.s., not significant;*; represent significant differences between treatments at $P<0.05$. Means followed by the same letter in each column were not significantly different according to the SNK test $(P \leq 0.05)$. 
Table 5. Chemical analyses of CON and DEFs wines (mean value and standard deviation).

\begin{tabular}{lccccccccc}
\hline \multicolumn{10}{c}{ Parameters } \\
\hline Wine & $\boldsymbol{p H}$ & $\boldsymbol{T} \boldsymbol{A}$ & $\boldsymbol{V A}$ & $\boldsymbol{A S}$ & $\boldsymbol{D M}$ & $\boldsymbol{R} \boldsymbol{C}$ & $\boldsymbol{C}$ & $\boldsymbol{C H}$ & $\boldsymbol{G I}^{*}$ \\
\hline CON & $3.82 \pm 0.04 \mathrm{a}$ & $6.30 \pm 0.16 \mathrm{~b}$ & $0.4 \pm 0.03$ & $14.60 \pm 0.12 \mathrm{a}$ & $34.00 \pm 1.23 \mathrm{a}$ & $2.20 \pm 0.50$ & $19.39 \pm 0.90 \mathrm{a}$ & $0.53 \pm 0.03$ & 33.23 \\
DEF I & $3.71 \pm 0.03 \mathrm{~b}$ & $6.58 \pm 0.18 \mathrm{~b}$ & $0.38 \pm 0.02$ & $13.90 \pm 0.35 \mathrm{~b}$ & $31.25 \pm 1.02 \mathrm{~b}$ & $2.08 \pm 0.24$ & $14.03 \pm 1.67 \mathrm{~b}$ & $0.54 \pm 0.09$ & 32.52 \\
DEF II & $3.77 \pm 0.04 \mathrm{ab}$ & $7.13 \pm 0.23 \mathrm{a}$ & $0.42 \pm 0.02$ & $14.60 \pm 0.10 \mathrm{a}$ & $33.33 \pm 1.43 \mathrm{ab}$ & $2.03 \pm 0.23$ & $15.05 \pm 2.43 \mathrm{~b}$ & $0.49 \pm 0.08$ & 34.92 \\
\hline
\end{tabular}

Legend: CON: Control, no defoliation; DEF I: leaves removal at the beginning of veraison; DEF II: leaves removal at the end of veraison; TA: Titratable acidity ( $\mathrm{g} / \mathrm{L}$ expressed in tartaric acid); VA: Volatile acidity (expressed in $\mathrm{g} / \mathrm{L}$ of acetic acid); AS: alcohol strenght (\%); DM: Total dry matter (g/L); RS: Reducing sugars $(\mathrm{g} / \mathrm{L})$; CI: Color intensity (AU); $\mathrm{CH}$ : Color hue (AU); GI: *Gelatin index (average of two replicates). Unless specified data are the mean value of four indipendent vinification (replicates). The letters represent the results of Fisher's LSD comparison tests: different letters on the column indicate means significantly different $(\alpha=0.05)$ among different wines.

Table 6. Composition of CON and DEFs wines for anthocyanins and simple phenolic compounds (mean value and standard deviation).

\begin{tabular}{|c|c|c|c|}
\hline Parameter $(\mathrm{mg} / \mathrm{L})$ & $\mathrm{CON}$ & DEF I & DEF II \\
\hline \multicolumn{4}{|c|}{ Anthocyanins* } \\
\hline Df-3-gle & $26.06 \pm 8.49$ & $24.64 \pm 2.91$ & $25.97 \pm 4.26$ \\
\hline Cn-3-glc & $2.65 \pm 0.38 \mathrm{a}$ & $2.27 \pm 0.05 \mathrm{~b}$ & $2.38 \pm 0.12 \mathrm{ab}$ \\
\hline Pt-3-glc & $33.18 \pm 9.37$ & $27.79 \pm 1.86$ & $29.64 \pm 5.51$ \\
\hline Pn-3-glc & $7.88 \pm 2.51$ & $5.82+0.19$ & $6.56 \pm 0.71$ \\
\hline$M v-3$-glc & $239.28+62.20$ & $186.25 \pm 23.45$ & $200.24+27.21$ \\
\hline Df-3-acetylglc & $6.47 \pm 1.55$ & $6.08+0.66$ & $7.08+0.52$ \\
\hline Cn-3-acetylglc & $3.60 \pm 0.46$ & $3.17 \pm 0.10$ & $3.16+0.15$ \\
\hline Pt-3-acetylglc & $9.89 \pm 2.27$ & $8.67 \pm 0.71$ & $8.64+1.05$ \\
\hline Pn-3-acetylgle & $5.74 \pm 1.50$ & $5.16 \pm 0.20$ & $5.59 \pm 0.75$ \\
\hline Mv-3-acetylglc & $66.02 \pm 14.26$ & $52.16 \pm 7.93$ & $54.41 \pm 7.15$ \\
\hline Df-3-coumaroylglc & $3.16 \pm 0.55$ & $3.29 \pm 0.26$ & $3.22 \pm 0.24$ \\
\hline Cn-3-coumaroylgle & $2.24 \pm 0.24$ & $2.32+0.11$ & $2.33 \pm 0.02$ \\
\hline Pt-3-coumaroylgle & $4.15 \pm 0.59 \mathrm{a}$ & $3.40 \pm 0.36 \mathrm{~b}$ & $3.27 \pm 0.13 \mathrm{~b}$ \\
\hline $\mathrm{Pn}+\mathrm{Mv}$ coumaroylglc & $22.76 \pm 5.19 \mathrm{a}$ & $15.10 \pm 2.81 \mathrm{~b}$ & $15.93 \pm 2.30 \mathrm{~b}$ \\
\hline Total anthocyanins & $433.14 \pm 107.34$ & $346.18 \pm 37.66$ & $368.47 \pm 47.73$ \\
\hline \multicolumn{4}{|l|}{ Phenolic acids } \\
\hline Protocatechuic & $0.91 \pm 0.40 \mathrm{~b}$ & $1.78 \pm 0.39 \mathrm{a}$ & $1.47 \pm 0.42 \mathrm{ab}$ \\
\hline Gallic & $26.97 \pm 2.01 \mathrm{a}$ & $23.06 \pm 1.63 \mathrm{~b}$ & $25.06 \pm 2.33 \mathrm{ab}$ \\
\hline \multicolumn{4}{|l|}{ Cinnamic acids } \\
\hline Caffeic & $2.30 \pm 0.66$ & $1.86 \pm 0.10$ & $2.39 \pm 0.41$ \\
\hline Coutaric & $47.61 \pm 5.10 \mathrm{a}$ & $38.04 \pm 4.68 \mathrm{~b}$ & $41.05 \pm 4.75 \mathrm{ab}$ \\
\hline Caftaric & $137.12 \pm 2.57 \mathrm{a}$ & $120.80 \pm 7.63 \mathrm{~b}$ & $127.13 \pm 8.15 \mathrm{ab}$ \\
\hline Coumaric & $1.26 \pm 0.09$ & $1.59 \pm 0.27$ & $1.73 \pm 0.11$ \\
\hline \multicolumn{4}{|l|}{ Flavanols } \\
\hline (+)-Catechin & $307.69 \pm 34.59$ & $245.28+47.26$ & $276.99 .0 \pm 50.59$ \\
\hline (-)-Epicatechin & $90.23 \pm 5.89 \mathrm{a}$ & $81.16 \pm 10.19 a b$ & $78.28 \pm 5.19 \mathrm{~b}$ \\
\hline \multicolumn{4}{|l|}{ Flavonols } \\
\hline Rutin & $5.83 \pm 1.11 \mathrm{ab}$ & $7.50 \pm 1.44 \mathrm{a}$ & $5.36 \pm 0.57 b$ \\
\hline Myricetin & $3.80 \pm 0.52 \mathrm{a}$ & $2.08 \pm 0.24 \mathrm{c}$ & $2.90 \pm 0.35 \mathrm{~b}$ \\
\hline Quercetin & $2.20 \pm 0.26$ & $1.66 \pm 0.83$ & $1.74 \pm 0.31$ \\
\hline \multicolumn{4}{|l|}{ Hydroxy stilbenes } \\
\hline Trans-resveratrol & $2.15 \pm 0.24 \mathrm{a}$ & $1.40 \pm 0.25 \mathrm{~b}$ & $1.55 \pm 0.06 \mathrm{~b}$ \\
\hline
\end{tabular}

*Df: Delphinidin; Cn: Cyanidin; Pt: Petunidin; Pn: Peonidin; Mv: Malvidin; glc: glucoside; acetylglc: 6-O-acetylglucoside; coumaroylglc: 6-O-(p-coumaroyl)-glucoside. The letters represent the results of Fisher's LSD comparison tests: different letters on the column indicate means significantly different $(\alpha=0.05)$ 


\subsection{Sensory analysis}

In order to corroborate the analytical data a sensory test finalized to evaluate the astringency among wine samples was performed. Two tasting sessions were set up in which assessors tasted three wine combinations (CON vs. DEF I; CON vs DEF II, DEF I vs DEF II). Although no differences emerged in the comparison among $\mathrm{CON}$ and DEFs wines, in both testing session assessors evaluated the DEF I wines as less astringent than DEF II wines.

\section{Discussion}

The research showed the marked impact of defoliation on the chemical and physical characteristics of the grapes and wine. The decrease in the berry soluble solids concentration of defoliated vines (Table 3 ) could be partially related to the diminution of photosynthesis products exported from the leaves to the grapes due to the reduction of photosynthetically active leaf area. Moreover, defoliation at veraison induced an early diminishing effect on sugar transport and flavonoid synthesis, during berry skin ripening (Matus et al. 2009). A down-regulation of the grape HEXOSE TRANSPORTER1 (HT1) that could be related to a decrease in source organ potential was found (Matus et al. 2009).

Through the imposition of DEFs treatments a small portion of total leaf area was removed, mainly consisting of old leaves, with a relatively low photosynthetic capacity compared to those inserted into the upper nodes of the main shoot. Besides, the effects on plant photosynthetic capacity and the alteration of light and thermal conditions at bunch level, leaf removal can modify berry metabolism through additional multiple mechanisms (e.g. synthesis of hormones, source of nutrients).

The decrease in yeast available nitrogen (YANC), observed in DEFs treatments, could be linked to the contribution, via phloema, of the old basal leaves of the shoot to the accumulation of such nutrient at bunch level (Conradie 1991). Light deprived berries of cv. Uva Longanesi showed a marked decrease in soluble solids compared to the other treatments (Table 3). The lower sugar concentration of non-exposed fruits (Table 3 ) could be related to a reduction in the concentration or activity of invertase or other enzymes involved in the regulation of sugar accumulation (Dokoozlian and Kliewer 1996). However, several studies indicate that fruit shading does not significantly affect the accumulation of total soluble solids (Morrison and Noble 1990, Haselgrove et al. 2000, Downey et al. 2004).

Uva Longanesi variety presented an anthocyanin profile characterized by a strong predominance of tri-hydroxylated anthocyanins (Table 4), and in contrast with other cultivars, including Muscat Rouge de Madere, Moscato Rosa, and Nebbiolo, which accumulate mainly di-substituted anthocyanins (Castellarin et al. 2011). Malvidin 3 -glucoside was the most prevalent anthocyanin detected in grapes from cv. Uva Longanesi (Table 4). The type of acylation of the glucose moiety vary among varieties (Mattivi et al. 2006). In cv. Uva Longanesi monoglucoside anthocyanins with no acylation predominate over acetylglucosides and p-coumarilglucosides and Malvidin-3-acetylglucosyde was the major acylated anthocyanins (data not shown). Uva Longanesi grapes anthocyanin profile is different to that of cv. Sangiovese, one of the 
most important local variety, whose acylated anthocyanin content is extremely low (Mattivi et al. 2006, Castellarin et al. 2011). In highbush blueberry (Vaccinium corymbosum) high amounts of delphinidin aglycone were detected and the main skin anthocyanins were petunidin3-glucoside and petunidin-3-arabinnoside, followed by malvidin-3-galactoside (Ribera et al. 2010).

A decrease in the concentration of 3-glycosylated peonidin and malvidin (Table 4) was observed in Uva Longanesi plants subjected to defoliation. The relationship between anthocyanin composition and defoliation at veraison seems to be cultivar dependent, since this treatment promoted a general increase in anthocyanin accumulation in Cabernet Sauvignon berries (Matus et al. 2009), but a variety dependent increase in determined 3-glycosilated anthocyanins in Sangiovese (Pastore et al. 2013) berries. Defoliation altered the thermal (Tables 1 and 2) and light regime at the cluster level. Therefore, the observed differences can be attributed also to light and/or temperature. However, in this experiment, light did not seem to have altered the anthocyanins level in the skin. No differences between treatments DEF II and DEF II + SH (Table 4) that differ especially for the light regime and only minimally to the thermal, were detected.

Studies on cv. Pinot Noir, Emperor, and Reliance showed that the clusters maintained in the absence of light undergo a clear decrease in anthocyanins concentration, sometimes associated with qualitative variations of these compounds (Kliewer 1977, Gao and Cahoon 1994). Anthocyanins accumulation and their profile in Merlot berries appeared to be determined by a synergistic combination of solar radiation and berry temperature and that this latter parameter was a strong environmental determinant of anthocyanin profile in the berry skins, above a potentially low threshold of exposure to solar radiation (Tarara et al. 2008). In cv. Uva Longanesi, the accumulation of anthocyanins does not appear to be influenced by light (Table 4) and, in relation to this aspect, it looks similar to cv. Shiraz (Downey et al. 2004), whose shaded fruits colored normally and in two of the three season of the experiment did not show significant change in anthocyanin concentration. The decrease of berry anthocyanins in defoliated vines (Table 4) is probably mainly due to the high temperatures, which exceeded $38{ }^{\circ} \mathrm{C}$ in bunches exposed to light (Table 1 and 2) that could have overridden the positive effects of cluster light exposure. High temperatures (max $35^{\circ} \mathrm{C}$ ) at the level of the skin caused a decrease in anthocyanin concentration (Mori et al. 2007). The temperature values detected during this experiment on the portion of the bunch exposed to light are above the optimum range for the activity of enzymes involved in flavonoid synthesis, such as Phenylalanine-ammonia-lyase (PAL) and chalcone isomerase (CHI), whose activity increases sharply at the beginning of veraison and decrease rapidly thereafter. Data suggest that temperature has more effect on anthocyanin accumulation than light (Spayd et al. 2002, Mori et al. 2005, Tarara et al. 2008) and seems to indicate that clusters exposure to high temperatures, at the beginning of veraison, can reduce anthocyanins accumulation (Table 4). In a recent research defoliating cv. Sangiovese at veraison had a detrimental effect on anthocyanin (Pastore et al. 2013); this aspect, could have adverse effects on wine composition and quality, since the cv. Sangiovese is known for not having 
an intense color (Sartini et al. 2000). According to these authors, the impact of leaf removal on berries combined with the highest air temperature during the season may have inhibited anthocyanin synthesis and promoted their degradation. The ratio between tri-hydroxilated and di-hydroxylated anthocyanins was higher in berries of plant defoliated at veraison, reflecting the greater accumulation of cyanidin and the lower accumulation of malvidin during ripening (Pastore et al. 2013). In our work, this parameter, at veraison was similar in all treatments. This would confirm that the relationship between the composition in anthocyanins and leaf removal at veraison could be also cultivar dependent (Matus et al. 2009, Pastore et al. 2013). Currently ideal conditions for anthocyanin accumulation in grapes are still unknown and it has not yet been established whether their accumulation concerns an integrated response to temperature in terms of thermal time, to specific threshold temperatures, or to a duration of exposure to critical temperatures (Tarara et al. 2008).

Defoliation performed at onset of veraison caused a significant decrease of anthocyanins concentration in berries (Table 4). In wine, although higher concentration of total anthocyanins were recorded in $\mathrm{CON}$, the difference among canopy managements was not statistically significant (Table 6). However, differences among single phenolic compounds were highlighted and total color intensity was higher in CON wine (Tables 5 and 6).

Uva Longanesi wines are generally characterized by high values of total phenols, including anthocyanins (Fontana 2000) and the DEFs wines, in spite of the decreased color intensity, still have high level of this parameter. This result is noteworthy as a decline in anthocyanin concentration, in varieties lacking in color (e.g. cv. Sangiovese), could have somewhat negative consequences on the derived wine characteristics. This strongly highlight the relevance of complementary viticultural and enological research, aimed to elucidate whether the impact of cultural practices on berry physiology and biochemical characteristics results in an actual drawback / advantage for wines organoleptic and chemical properties.

In general, all wines were characterized by a high AS, DM and CI thus confirming previous results that deem Uva Longanesi variety suitable to produce wines with desired body and structure (Sartini et al. 2000). As regard the effect of canopy management, no-defoliation (CON) and defoliation at the end of veraison (DEF II) determined comparable effect on $\mathrm{pH}$ (3.82 vs 3.77 ), alcohol strength (14.60 vs $14.60 \%)$ and total dry matter (34.0 vs $33.3 \mathrm{~g} / \mathrm{L})$. Defoliation at the beginning of veraison (DEF I) resulted in a significant reduction of alcohol strength (13.90\%) in comparison with CON (14.60\%) and DEF II (14.60\%) as well as a decrease of $\mathrm{pH}$ and dry matter and color intensity with respect to CON (Table 5). The DEF II wines showed $\mathrm{pH}$ values similar to CON and DEF I wines. It is well known that astringency perception is based on protein-tannins interaction and that the interaction is depending on $\mathrm{pH}$ of the medium. Our results suggest that $\mathrm{pH}$ didn't affect the perception of astringency in these wines. In DEF II the main effect was represent by a high total acidity (Table 5). At last, the VA, RS and $\mathrm{CH}$ were comparable in all wines irrespective of the extent of plant defoliation (Table 5). 


\section{Conclusions}

Sensory astringency is a focal point for Uva Longanesi wines and the possibility to obtain less astringent / "more round" wines, through the targeted application of a strongly recommended canopy management practice, is very attractive to winemakers. Remarkable results were achieved in sensory evaluation: wines obtained from plants defoliated at the onset of veraison resulting less astringent when compared to wines obtained from end of veraison-defoliated plants. These results were confirmed by gelatin index analysis (Table 5). Defoliation at the beginning of veraison, contributed markedly to the reduction of wine alcohol content $(-0.5 \% \mathrm{TAV})$. This aspect should be further investigated given the market demand for lowalcohol content wines. Moreover, the possibility of slowing down berry sugar accumulation, through canopy management practices, is of paramount importance in organic farming. In fact, the regulation (Reg. EC. 203/2012) for the production of organic wine, forbid the use of techniques, such as dealcoholization, to correct wine alcohol strength.

Analytical data demonstrated a great effect of defoliation at the end of veraison (DEF II) in total acidity, whereas both defoliation treatments affected wine color intensity (Table 5). This aspect has not to be matter of concern in a wine such as Uva Longanesi constantly characterized by a high color intensity (e.g. CON: 19.39 AU). The elucidation of the mechanisms by which the removal of a small number of mature basal leaves can induce marked changes on chemical properties of berries and wines represent a stimulating challenge for future research.

\section{Aknowledgments}

The authors gratefully acknowledge the FAPESP (São Paulo, Brazil) for the post-doc scholarship to Aparecida Conceição Boliani and the CNPq for the post-doc scholarship to Renato Vasconcelos Botelho and the student scholarship to Carine Rusin within the CsF Program. This study was supported by CEVICO Group Soc. Coop Agricola and Azienda Agricola Graziani, Bagnacavallo (RA). The authors are grateful to Dott.ssa Greta Bertaccini for her contribution to field measurements and laboratory analysis.

\section{References}

Alfaro, S., Mutis, A., Palma, R., Quiroz, A., Seguel, I., Scheuermann, E. 2013. Influence of genotype and harvest year on polyphenol content and antioxidant activity in murtilla (Ugni molinae Turcz) fruit. Journal of Soil Science and Plant Nutrition. 13(1), 67-78.

Arfelli, G., Chiavari, G., Castellari, M., Amati, A. 1992. Influenza della tecnica di vinificazione sul contenuto di sostanze polifenoliche di vini ottenuti da cultivar diverse. Analisi HPLC dei composti polifenolici dei mosti e dei vini. Vignevini. 19, 53-58.

Arpa Emilia-Romagna, 2009. Regional Agency for the prevention and the environment of Emilia-Romagna (www.arpa.emr.it).

ASTM Standard definitions of terms relating to sensory evaluation of materials and products. 1989. In Annual Book of ASTM; American Society of Testing and Materials: Philadelphia, PA. 
Bergqvist, J., Dokoozlian, N., Ebisuda, N. 2001. Sun-light exposure and temperature effects on berry growth and composition of Cabernet sauvignon and Grenache in the central San Joaquin valley of California. Am. J. Enol. Vitic. 52, 1-7.

Bledsoe, A.M., Kliewer, W.M., Marois, J.J. 1998. Effects of timing and severity of leaf removal on yield and fruit composition of Sauvignon blanc grapevines. Am. J. Enol. Vitic.1, 49-54.

Castellari, M., Sartini, E., Fabiani, A., Arfelli, G., Amati, A. 2002. Analysis of wine phenolics by high performance liquid chromatography using a monolithic type column. Journal of Chromatography A. 973, 221-227.

Castellarin, S. D., Bavaresco, L., Falginella, L., Van Zeller Gonçalves, M. I., Di Gaspero, G. 2011. Phenolics in grape berry and key antioxidants. In: The biochemistry of the grape berry. Gerós H., Chaves M., Delrot S. (Eds), pp 89-110 Bentham Science Publishers.

Conradie, W. 1991. Distribution and Translocation of Nitrogen Absorbed During Early Summer by Two-Year-Old Grapevines Grown in Sand Culture. Am. J. Enol. Vitic.42, 180-190.

Chorti, E., Guidoni, S., Ferrandino, A., Novello, V. 2010. Effect of different cluster sunlight exposure levels on ripening and anthocyanin accumulation in Nebbiolo grapes. Am. J. Enol. Vitic. 61, 23-30.

Diago, M.P., Vilanova, M., Blanco, J.A., Tardaguila, J. 2010. Effects of mechanical thinning on fruit and wine composition and sensory attributes of Grenache and Tempranillo varieties (Vitis vinifera L.). Aust. J. Grape Wine Res. 16, 314-326.
Dokoozlian, N., Kliewer, W. 1996. Influence of light on grape berry growth and composition varies during fruit development. Journal of the American Society for Horticultural Sciences. 121, 869-874.

Downey, M., Harvey, J., Robinson, S. 2004. The effect of bunch shading on berry development and flavonoid accumulation in Shiraz grape. Aust. J. Grape Wine Res. 10, 55-73.

European Official Methods (Gazzetta Ufficiale, CE, 2676/90).

Fontana, M. 2000. Authorization of three new grape varieties. Agricoltura. 10, 69-71.

Gao, Y. and Cahoon, G. 1994. Cluster shading effects on fruit quality, fruit skin color, and anthocyanin content and composition in Reliance (Vitis hybrid). Vitis. 33, 205-209.

Guidoni, S., Ferrandino, A., Novello, V. 2008. Effects of seasonal and agronomical practices on skin anthocyanin profile of Nebbiolo grapes. Am. J. Enol. Vitic. 59, 22-29.

Glories, Y. 1978. Thèse doctoral en sciences Recherches sur la matiére colorante des vins rouges. Universitè de Bordeaux II France.

Haselgrove, L., Botting, D., van Heeswijck, R., Hoj, P., Dry, P., Ford, C., Iland, P. 2000. Canopy microclimate and berry composition: The effect of bunch exposure on the phenolic composition of Vitis vinifera L. cv. Shiraz grape berries. Aust. J. Grape Wine Res. 6, 141-149.

Intrieri, C., Filippetti, I., Allegro G., Centinari, M., Poni S. 2008. Early defoliation (hand vs mechanical) for improved crop control and grape composition in Sangiovese (Vitis vinifera L.). Aust. J. Grape Wine Res. 14, 25-32. 
ISO 3591, 1977. Sensory Analysis. Apparatus Wine tasting glass. Geneva, Switzerland.

Kelm, M.A., Versari, A., Parpinello, G.P., Thorngate, J.H. 2012. Mass Spectral Characterization of Uva Longanesi Seed and Skin Extracts, Am. J. Enol. Vitic. 63, 402406.

Kliewer, W. 1977. Influence of temperature, solar radiation and nitrogen on coloration and composition of Emperor grapes. Am. J. Enol. Vitic. 28, 96-103.

Kriedemann, P.E., Kliewer, W.M., Harris, J.M. 1970. Leaf age and photosynthesis in Vitis vinifera L. Vitis. 9, 97-104.

Lawless, H., Heymann, H. 1998. Sensory Evaluation of Food: Principles and Practices. New York: Chapman and Hall.

Li, J.H., Guan, L., Fan, P.G., Li, S.H., Wu, B.H. 2013. Effect of Sunlight Exclusion at Different Phenological Stages on Anthocyanin Accumulation in Red Grape Clusters. Am. J. Enol. Vitic. 64, 349-356.

Marangoni, B., Ventura, A., Fontana, M. 2000. Uva Longanesi. Vignevini, 7/8, 63-67.

Matus, J.T., Loyola, R., Vega, A., Pena-Neira, A., Bordeu, E., Arce-Johnson, P., Alcalde, J.A. 2009. Post-veraison sunlight exposure induces MYB-mediated transcriptional regulation of anthocyanin and flavonol synthesis in berry skins of Vitis vinifera. Journal of Experimental Botany. 60, 853867.

Mattivi, F., Guzzon, R., Vrhovsek, U., Stefanini, M., Velasco, R. 2006. Metabolite profiling of grape: flavonols and anthocyanins. J. Agric. Food Chem. 54, 7692-7702.
Mori, K., Sugaya, S., Gemma, H. 2004. Regulatory mechanism of anthocyanin biosynthesis in 'Kyoho' grape berries grown under different temperature conditions. Environment Controlol in Biology. 42, 2130.

Mori, K., Sugaya, S. Gemma, H. 2005. Decreased anthocyanin biosynthesis in grape berries grown under elevated night temperature condition. Scientia Horticulturae. 105, 319330 .

Mori, K., Goto-Yamamoto, N., Kitayama, M., Hasizume, K. 2007. Loss of anthocyanins in red-wine grape under high temperature. Journal of Experimental Botany. 58, 19351945.

Morrison, J., Noble, A. 1990. The effects of leaf and cluster shading on the composition of 'Cabernet sauvignon' grapes and on fruit and wine sensory properties. Am. J. Enol. Vitic. 41, 193-200.

Palliotti, A., Gatti, M., Poni, S. 2011. Early Leaf Removal to Improve Vineyard Efficiency: Gas Exchange, Source-to-Sink Balance, and Reserve Storage Responses. Am. J. Enol. Vitic.. 62, 219-228.

Palliotti, A., Panara, F., Silvestroni, O., Lanari, V., Sabbatini, P., Howell G.S., Gatti, M., Poni, S. 2013. Influence of mechanical postveraison leaf removal apical to the cluster zone on delay of fruit ripening in Sangiovese (Vitis vinifera L.) grapevines. Aust. J. Grape Wine Res. 19, 369-377.

Pastore, C., Zenoni, S., Fasoli, M., Pezzotti, M., Tornielli G. B., Filippetti, I. 2013. Selective defoliation affects plant growth, fruit transcriptional ripening program and flavonoid metabolism in grapevine. BMC Plant Biology. 13-30. 
Poni, S., Intrieri, C.,Silvestroni, O. 1994. Interactions of Leaf Age, Fruiting and Exogenous Cytokinins in Sangiovese Grapevines under Non-irrigated Conditions. I. Gas-exchange. Am. J. Enol. Vitic. 45, 7178.

Poni, S., Casalini, L., Bernizzoni, F., Civardi, S., Intrieri, C. 2006. Effects of early defoliation on shoot photosynthesis, yield components and grape composition. Am. J. Enol. Vitic. 57, 397-407.

Poni, S., Bernizzoni, F., Civardi, S., Libelli, N. 2009. Effects of pre-bloom leaf removal on growth of berry tissues and must composition in two red Vitis vinifera L. cultivars. Aust. J. Grape Wine Res. 15, 185-193.

Poni, S., Gatti, M., Bernizzoni, F., Civardi, S., Bobeica, N., Magnanini, E., Palliotti, A. 2013. Late leaf removal aimed at delaying ripening in cv. Sangiovese: physiological assessment and vine performance. Aust. J. Grape Wine Res. 19, 378-387.

Ribera, A.E., Reyes-Díaz, M., Alberdi, M., Zuñiga, G.E., Mora, M.L. 2013. Antioxidant compounds in skin and pulp of fruits change among genotypes and maturity stages in highbush blueberry (Vaccinium corymbosum L.) grown in southern Chile. J. Soil. Sci. Plant Nutr. 10 (4): 509 - 536.
Ripper M. and Schmitt E., 1896. Zeitschift f.a.ch. XXXV, 232.

Sampaio, T., Kennedy, J., Vasconcelos, M. 2007. Use of Microscale Fermentations in grape and wine research. Am. J. Enol. Vitic. 58, 534-539.

Sartini, E., Parpinello G.P., Galassi, S., Versari, A. 2000. Characterization of Uva Longanesi Red Wine by Selected Parameters Related to Astringency. International Journal of Food Properties. 14, 1081-1089.

Spayd, S., Tarara, J., Mee, D., Ferguson, J. 2002. Separation of Sunlight and Temperature Effects on the Composition of Vitis vinifera cv. Merlot Berries. Am. J. Enol. Vitic. 53, 171-182.

Tarara, J.M., Lee, J., Spayd, S E., Scagel, C.F. 2008. Berry temperature and solar radiation alter acylation, proportion, and concentration of anthocyanin in Merlot grapes. Am. J. Enol. Vitic. 59, 235-247.

Yamane, T., Jeong, S., Goto-Yamamoto, N., Koshita, Y., Kobayashi, S. 2006. Effects of temperature on anthocyanin biosynthesis in grape berry skins. Am. J. Enol. Vitic. 57, 5459. 